\title{
HOME APPLIANCES CONTROLING WITH MOBILE DEVICE BASED ON ANDROID OPERATING SYSTEM
}

\author{
Padeli $^{1}$ \\ Sudaryono ${ }^{2}$ \\ Nursohit $^{3}$ \\ Dosen AMIK Raharja Informatika ${ }^{1}$, Dosen STMIK Raharja ${ }^{2}$ \\ Mahasiswa program studi Sistem Komputer STMIK Raharja ${ }^{3}$ \\ E-mail: padeli@raharja.info ${ }^{1)}$, sudaryono@ raharja.info ${ }^{3)}, \underline{\text { nursohit@ raharja.info }}{ }^{2)}$
}

\begin{abstract}
ABSTRAK
Pengendalian peralatan listrik rumah tangga secara manual menyebabkan penggunaan tidak terkontrol dengan baik, apalagi jika pengontrolan yang harus dilakukan harus pada ruang yang berbeda dan lampu listrik yang dikontrol secara manual. Untuk menghemat waktu dan mengurangi resiko lupa mematikan lampu maka dibuatlah sistem pengontrolan menggunakan smartphone Operating Sistem Android karena mudah digunakan dan dapat dibawa kemana-mana. Operating Sistem open source milik google, yang diberi nama ANDROID sebagai alat pengontrolan dari jarak jauh (remote) dengan memanfaatkan jaringan internet nirkabel (wireless internet). Untuk mengontrol sebuah perangkat listrik rumah tangga diperlukan sebuah IP sebagai identitas dari perangkat tersebut, untuk itu perlu ditanamkan sebuah TCP/IP sebagai media penyimpanan IP. Selain itu TCP/IP Starter Kit juga berfungsi sebagai penghubung antara smartphone dengan perangkat yang akan menerjemahkan perintah yang dikirimkan oleh smartphone untuk dieksekusi mikrokontroler ATMega328. Mikrokontroller berperan sebagai otak bagi device hardware. Antara smartphone dan perangkat, masing - masing diberikan alamat identitas berupa IP Address, Subnet Mask dan Gateway sehingga keduanya dapat saling berkomunikasi. Pada penelitian menggunakan metode perancangan yang digambarkan dalam sebuah flowchart, kemudian pada metode pengujian menggunakan metode pengujian black box. Sistem untuk mengontrol lampu hanya menekan button yang ada pada layer android dan ketika berhasil maka akan tampil ON/OFF pada layer tersebut.
\end{abstract}

Kata Kunci: android, mikrokontroller, wireless, TCP/IP

\section{ABSTRACT}

Control of electrical household appliances manually causing uncontrolled use properly, especially if control is to be done must be in a different space and electric lights are controlled manually. To save time and reduce the risk forgot to turn off the lights then be made using the control system Operating System Android smartphone because it is easy to use and can be taken anywhere. Open source operating system owned by Google, which is named ANDROID as a means of controlling them remotely (remote) network using the wireless internet (wireless internet). To control a household electrical device required an IP as the identity of the device, for it needs to be a TCP / IP as IP storage media. Besides TCP / IP Starter Kit also serves as a liaison between smartphones with a device that will translate commands sent by smartphones to be executed ATmega328 microcontroller. Microcontroller acts as the brain for the hardware device. Between smartphones and devices, each each is given the address of identity in the form of IP Address, Subnet Mask, and Gateway settings so they can communicate with each other. In research using a design method which is described in a flowchart, and then on the testing method using black box testing methods. System to control the lights simply tapping a button that of the layer android and when successful it will show the ON / OFF switch on the layer.

Keywords: android, microcontroller, wireless, TCP / IP 


\section{PENDAHULUAN}

Android adalah sistem operasi untuk mobile device yang awalnya dikembangkan oleh Android Inc. Perusahaan ini kemudian dibeli oleh Google pada tahun 2005. Android dibuat berdasarkan kernel Linux yang dimodifikasi. Aplikasi Android ditulis dengan bahasa Java, menggunakan Java Core Libraries. Aplikasi Android dijalankan di atas VM bernama Dalvik Virtual Machine. Di dunia ini terdapat dua jenis distributor sistem operasi Android. Pertama yang mendapat dukungan penuh dari Google atau Google Mail Services (GMS) dan kedua adalah yang benar-benar bebas distribusinya tanpa dukungan langsung Google atau dikenal sebagai Open Handset Distribution (OHD)[1]. Android memiliki berbagai keunggulan sebagai software yang memakai basis kode komputer yang bisa didistribusikan secara terbuka (open source) sehingga pengguna bias membuat aplikasi baru di dalamnya. Android memiliki aplikasi native Google yang terintegrasi seperti pushmail Gmail, Google Maps, dan Google Calendar[1]. Kemajuankemajuan dalam bidang teknologi elektronika yang menuju ke arah sistem digital serta rangkaian terpadu telah mendorong terciptanya IC-IC yang semakin cepat dengan kemampuan proses yang tinggi dan akurat serta bentuk yang semakin kecil, tetapi dengan kemampuan yang lebih besar[2]. Waktu merupakan hal yang sangat berharga terhadap seseorang yang memiliki pekerjaan. Dengan berjalannya waktu, tingkat kesibukan setiap orang akan bertambah seiring dengan pekerjaannya. Sehingga seseorang memiliki sedikit waktu untuk mengurus atau memonitoring rumahnya sendiri. Hal ini menyebabkan seseorang harus memasang alat pengontrolan jarak jauh untuk memenuhi kebutuhan itu. Tetapi alat pengontrolan yang menggunakan remote memiliki keterbatasan kemampuan dalam pengendaliannya, jarak merupakan kendala utama karena apabila jarak antara alat yang dikontrol dengan pengontrol itu melewati batas toleransinya, maka peralatan tersebut tidak akan berfungsi dengan baik.

Untuk mengontrol device secara jarak jauh dengan media internet kita harus mempunyai alat yang didalamnya sudah terintegrasi dengan program yang mampu mengakses internet seperti Internet

Explorer, Mozilla Firefox, Google Chrome, Opera Mini, Safari dll. Smartphone android merupakan alat yang didalamnya mampu ditanam program untuk mengakses internet tersebut. memanfaatkan jaringan internet, maka pengontrolan device secara jarak jauh dapat kapanpun dan dimanapun. Untuk itu perlu dirancang sebuah aplikasi untuk mengontrol device dengan menggunakan media internet.

\section{METODE PENELITIAN}

Tujuan penelitian ini adalah untuk membuat sebuah sistem pengontrolan menggunakan rangkaian relay yang diaplikasikan sebagai pengontrolan lampu secara terpusat menggunakan smartphone dengan Operating Sistem android, jaringan yang dirancang dilengkapi dengan mikrokontroler ATMega328 sebagai pusat pengolahan data. Penelitian ini menggunakan dua metode, pertama menggunakan metode perancangan flowchart yaitu penggambaran secara grafik dari langkahlangkah dan urutan-urutan prosedur dari suatu program[3]. Kedua menggunakan metode black box yaitu merupakan metode perancangan data uji yang didasarkan pada spesifikasi perangkat lunak. Data uji dibangkitkan, dieksekusi pada perangkat lunak dan kemudian keluaran dari perangkat lunak diuji apakah telah sesuai dengan yang diharapkan[4].Hardware pada peralatan ini terdiri dari beberapa rangkaian elektonika yang dirancang sedemikian rupa sehingga menjadi satu suatu sistem jaringan yang dapat difungsikan untuk mengontrol lampu. Secara umum cara kerja rangkaian ini dapat dilihat pada gambar 1. 


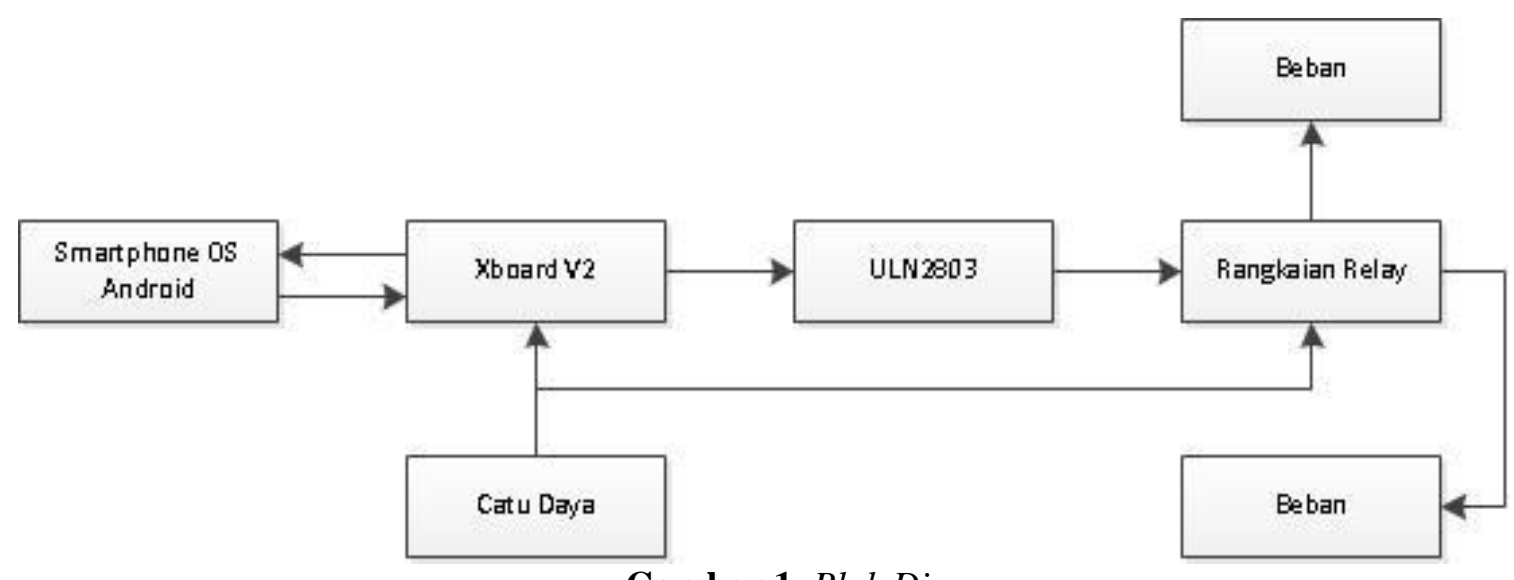

Gambar 1. Blok Diagram

Smartphone OS Android sebagai interface pengontrolan berfungsi untuk memberikan instruksi atau mengontrol peralatan listrik rumah tangga menggunakan jaringan wireless. Di mana instruksi yang dikirimkan melalui semartphone diterima oleh perangkat wireless dan diteruskan ke rangkaian XBoard V2. Di dalam Xboard V2 ini kemudian instruksi yang diterima berupa sinyal analog diproses oleh rangkaian Wiznet W5100 dan diubah menjadi sinyal digital. Setelah diubah menjadi sinyal digital kemudian diproses kembali oleh mokrokontroler ATMega328 dan hasil prosesnya diterima oleh rangkaian ULN2803. ULN2803 memberikan input kepada rangkaian relay sehingga rangkaian relay dapat berfungsi sebagai saklar otomatis untuk mengontrol lampu. Jika proses pengiriman data berhasil di proses secara keseluruhan maka mikrokontroler ini akan mengirimkan respond ke device android bahwa proses yang telah di request ke mikrokontroler berhasil di jalankan.

\section{PERANCANGAN PERANGKAT KERAS (HARDWARE)}

Hardware disini merupakan piranti tambahan yang berupa rangkaian elektronika dan merupakan peralatan penunjang yang terletak diluar computer. Rangkaian ini merupakan peralatan yang dikontrol oleh program dan dapat dikatakan sebagai kontak saklar dari lampu yang akan dikontrol[5].

1. Rangkaian Xboard V2

Di dalam rangkaian XBoard V2 ini memuat 2 rangkaian utama yaitu:

a. Rangkaian Wiznet W5100

W5100 merupakan single-chip internet yang memiliki fitur lengkap. Ethernet controller dirancang untuk aplikasi embedded di mana dalam pengoperasiannya memiliki kemudahan integrasi, stabilitas, kinerja, dan wiznet ini dirancang untuk memfasilitasi kemudahan pelaksanaan konektivitas internet tanpa OS. Wiznet W5100 merupakan chip yang sudah tertanam TCP/IP stack dan meng-implementasikan standard IEEE 802.3 (Ethernet Physical and Data Link Layer). 


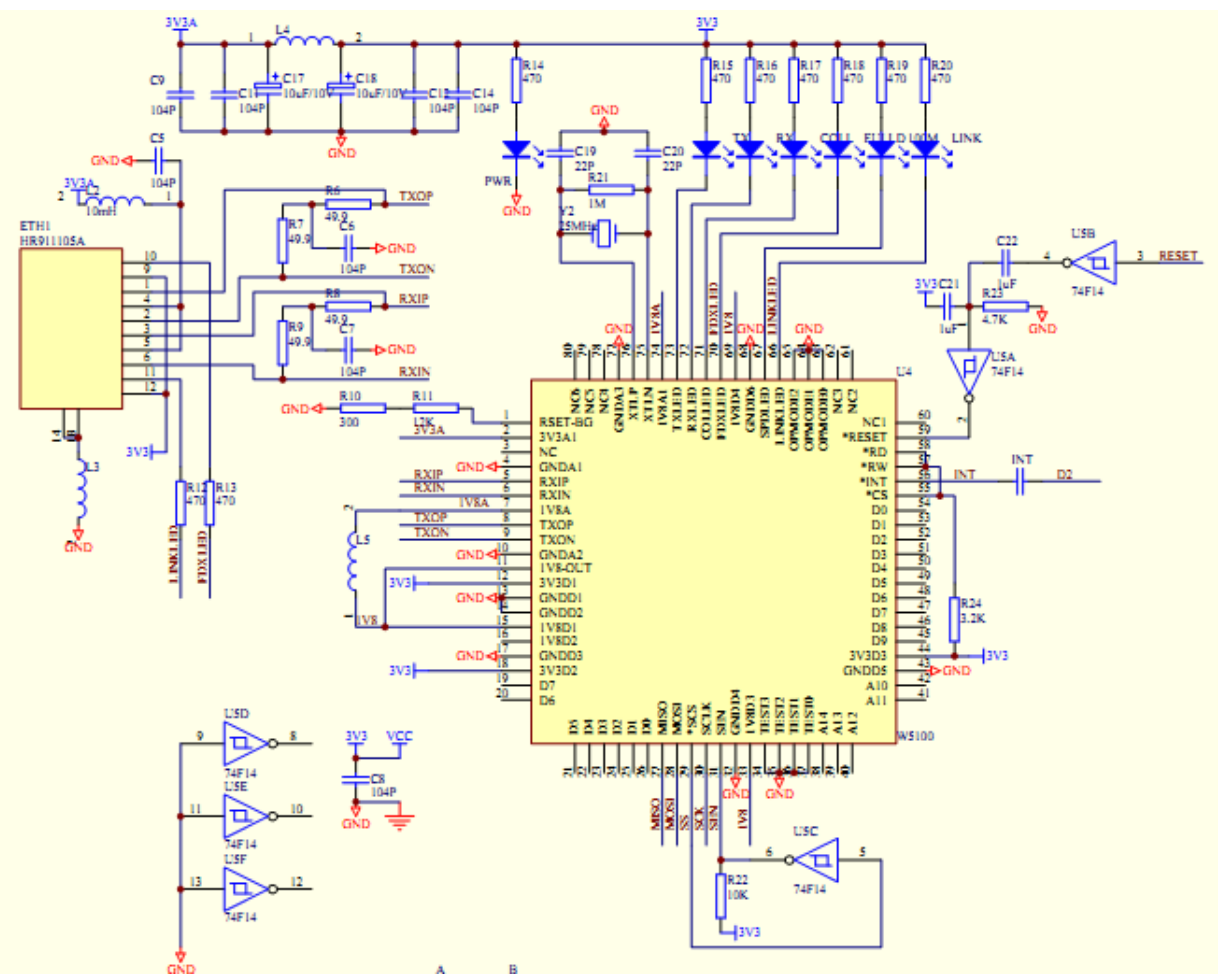

Gambar 2. Rangkaian Wiznet W5100

(sumber :skematic Xboard v2 2011)

a. Rangkaian Mikrokontroler ATMega328

ATMega328 merupakan mikrokontroler keluarga AVR 8 bit. Beberapa tipe mikrokontroler yang sama dengan ATMega8 ini antara lain ATMega8535, ATMega16, ATMega32, ATMega328, yang membedakan antara mikrokontroler antara lain adalah, ukuran memori, banyaknya GPIO (pin input/output), peripherial (USART, timer, counter, dll)[1].

Rangkaian mikrokontroler ini merupakan tempat pengolahan data dan pengoperasian alat. Dan dalam rancangan ini, mikrokontroler berfungsi sebagai otak dari seluruh sistem rancangan. Mikrokontroler ATMega328 memiliki 3 buah port dan berbagai pin yang digunakan untuk menampung input dan output data dan terhubung langsung dengan rangkaian-rangkaian pendukung lainnya. Port yang digunakan dalam pembuatan Home Appliance ini adalah port D. pembagian fungsi dari tiap-tiap portnya adalah sebagai berikut:

1. $\quad$ Port D0-D7 digunakan sebagai output dan input.

2. Pin XTAL1 merupakan saluran masukan ke rangkaian oscillator yang dihubungkan dengan Kristal yang memiliki frekuensi 11,0592 $\mathrm{MHz}$ dan dua buah kapasitor dengan nilai kapasitansi 22pf. Rangkaian oscillator pada mikrokontroler berfungsi untuk membentuk clock yang menentukan kecepatan kerja mikrokontroler.

3. Pin XTAL2 merupakan saluran keluaran penguat oscillator yang dihubungkan dengan cristal menuju ground melalui sebuah kapasitor. Pin ini juga sebagai pelengkap rangkaian oscillator pembentuk clock.

4. Pin reset pada mikrokontroler ATMega328 terletak pada pin 1(satu). Rangkaian Power On Reset ini menggunakan kapasitor $10 \mu \mathrm{F}$ dan resistor $10 \mathrm{~K} \Omega$. Yang membentuk rrangkaian power on reset dimana rangkaian ini akan mereset rangkaian mikrokontroler, sehingga mikrokontroler terseut kembali menjalankan program yang ada di dalamnya dari awal. Dan kondisi pada internal RAM tidak terjadi perubahan selama proses reset berlangsung. 


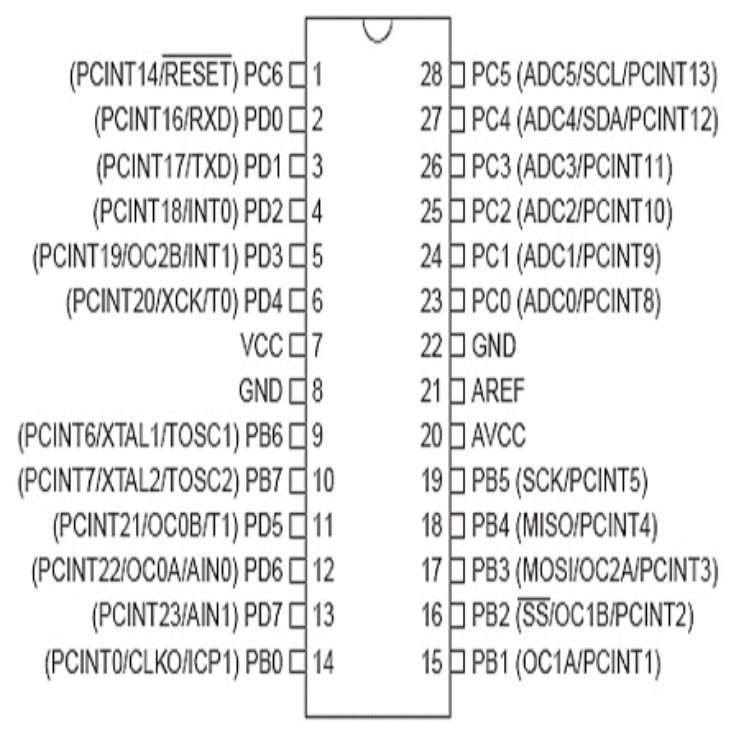

Gambar 3. Konfigurasi PIN ATMega328

(Sumber : jurnal ISSN : 2252-4908 (2012:34))

2. Rangkaian Driver ULN2803

Rangkaian ini merupakan rangkaian yang digunakan sebagai driver pengendali motor maupun relay. Dalam susunan ini rangkaian ini terdapat 18 pin yang masing-masing terdiri dari 9 pin yang digunakan sebagai inputan dan 9 pin lainnya digunakan sebagai output terhadap rangkaian relay. Dalam penyusunan rangkaian ini penulis hanya menggunakan 4 pin inputan dari pin 1 sampai pin 4 dan 4 pin sebagai output dari pin 15 sampai pin 18.



Gambar 4. Rangkaian ULN2803

(Sumber : datasheet ULN2803 @ Motorola, Inc. (1996:1))

\section{Rangkaian Relay}

Rangkaian ini berfungsi sebagai saklar otomatis dan juga sebagai hasil dari proses eksekusi mikrokontroler untuk menghidupkan dan mematikan lampu. Rangkaian ini membutuhkan catu daya sebesar $12 \mathrm{~V}$ DC agar relay dapat berfungsi dengan baik. Pin Output dari mikrokontroler di hubungkan dengan konektor J2.1 dan akan diproses oleh ULN2803 sehingga relay dapat berfungsi sesuai dengan input yang diterima oleh mikrokontroler. 


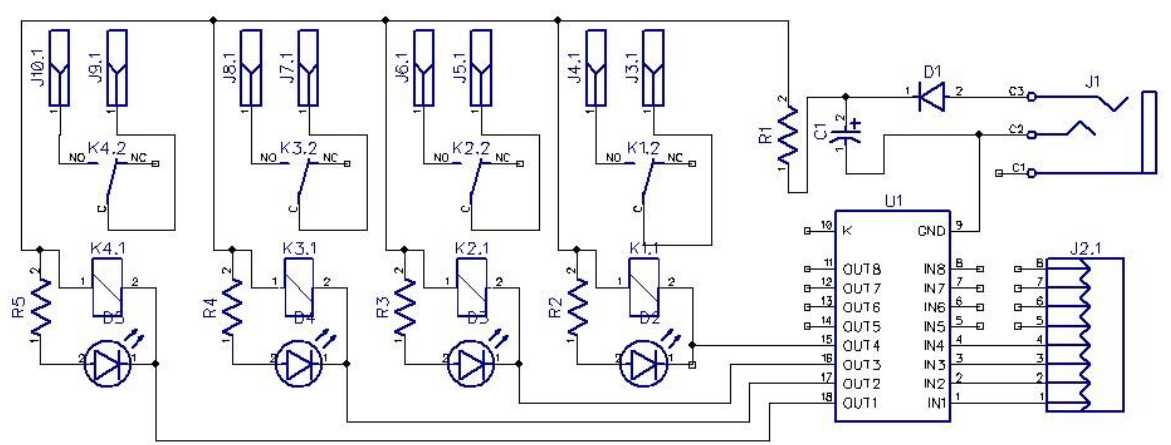

Gambar 5. Rangkaian relay

\subsection{PERANCANGAN PERANGKAT LUNAK (SOFTWARE)}

Perancangan program dengan diagram alir (flowchart). Pada pembuatan alat ini dibutuhkan program untuk pengendalikan semua proses kerja untuk mengontrol lampu. Untuk memudahkan pembuatan program diperlukan flowchart pada sistem pengontrolan smartphone android. Untuk lebih jelasnya lagi dapat kita lihat pada diagram alir dibawah ini.

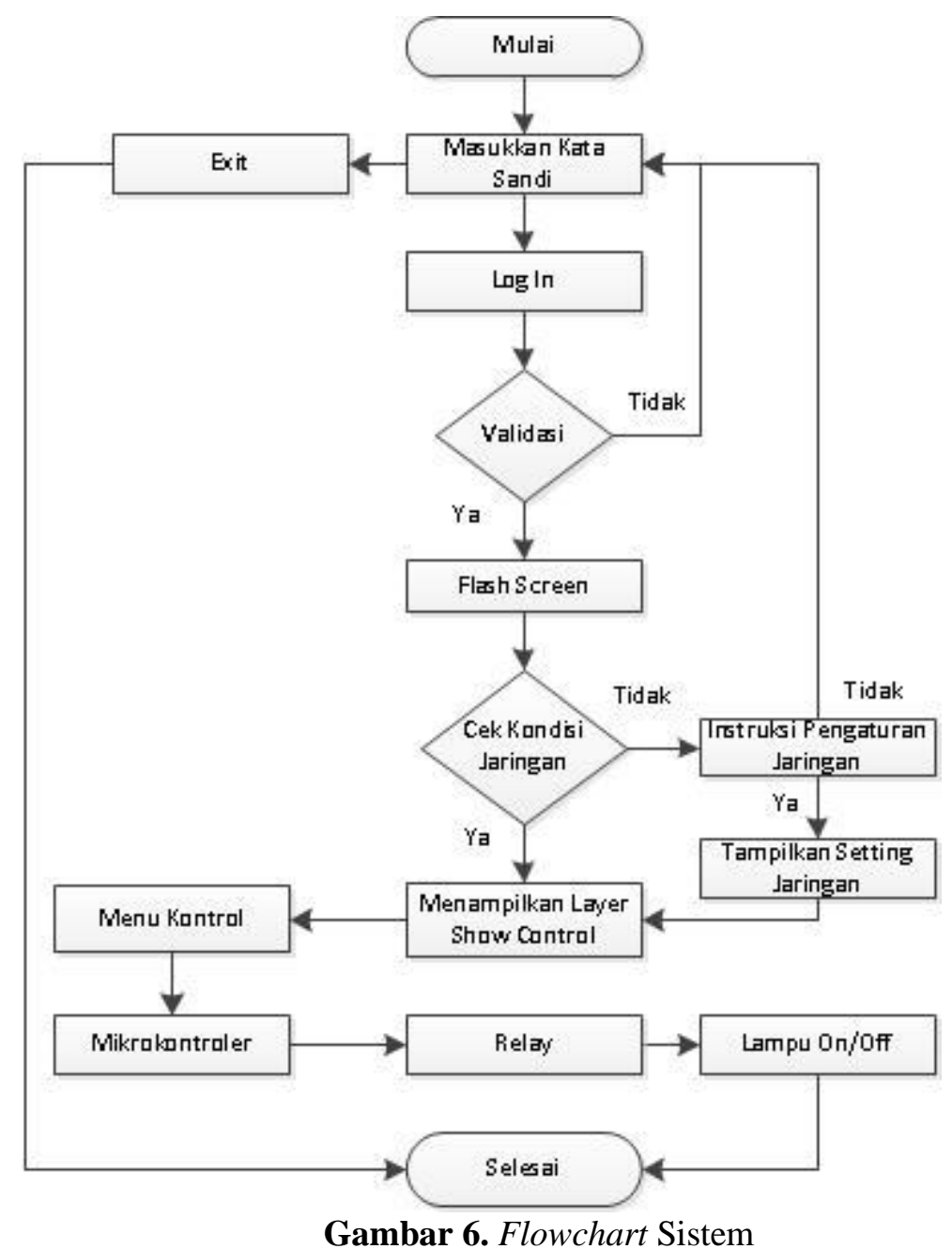

Cara kerja Flowchart Sistem diatas adalah sebagai berikut:

a. Pertama-tama user atau pengguna memasukkan kata sandi untuk masuk kedalam menu utama. Jika kata sandi yang dimasukkan benar maka akan tampil flash screen dan akan membuka layer kontrol. Jika salah maka akan muncul dialog message dan harus mengulangi langkah awal hingga benar. 
b. Urutan selanjutnya adalah setelah masuk kedalam menu kontrol maka sistem secara otomatis akan mengecek jaringan nirkabel apakah sudah ON/OFF. Jika OFF maka sistem akan menunjukkan instruksi untuk mengaktifkannya. Jika jaringan nirkabel sudah ON maka sistem kontrol siap digunakan.

c. Pada menu kontrol untuk menghidupkan dan mematikan lampu dengan menekan button ON/OFF. Setelah itu smartphone android akan mengirimkan string yang akan diterima oleh mikrokontroler.

d. Jika mikrokontroller mendapatkan request, maka request tersebut diproses dan hasilnya akan dikirim ke rangkaian relay untuk menghidupkan atau mematikan lampu.

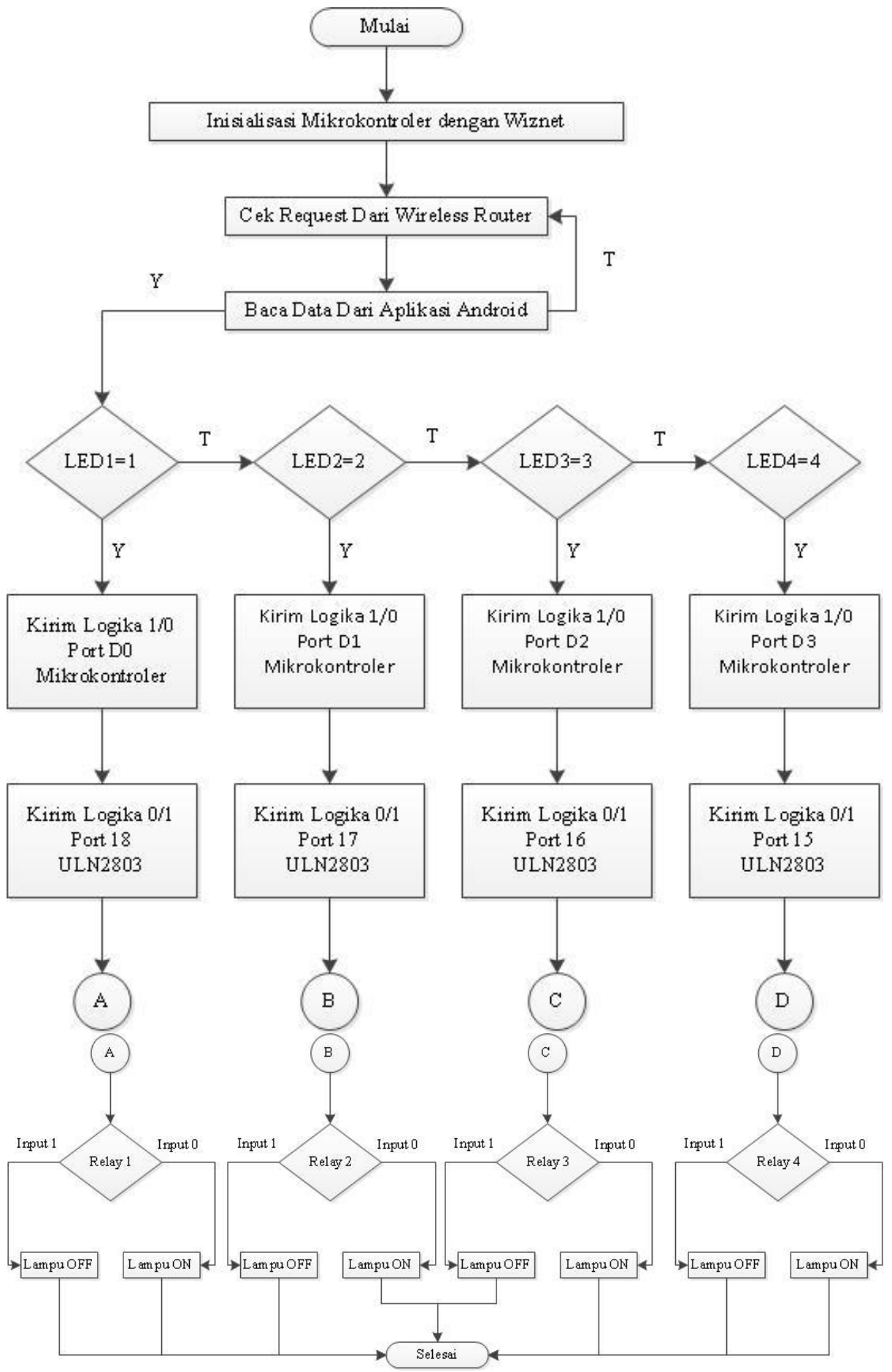

Gambar 7. Flowchart Program 
Cara kerja Flowchart Program diatas adalah sebagai berikut:

a. Pertama-tama mikrokontroler menginisialisasi rangkaian wiznet untuk mengecek apakah ada request yang datang atau tidak.

b. Jika terdapat request maka sistem siap mengirim data ke mikrokontroler untuk mengatur jalur komunikasi data, dimana mikrokontroler akan mendeteksi sistem telah siap atau tidak dengan mengirim kode masing - masing rangkaian output dari mikrokontroler.

c. Setelah pmrosesan data selesai maka mikrokontroler akan mengirimkan logika 1 yang menandakan bahwa terdapat request dari aplikasi R-CP1 dan akan langsung menjalankan pengiriman data.

d. Jika mikrokontroller mengirim data ke PC maka PC akan bersifat Standby untuk melanjutkan instruksi selanjutnya, dimana PC akan selalu menunggu apakah ada pengiriman dari mikrokontroler.

\section{HASIL DAN PEMBAHASAN}

Pengujian ini dilakukan setelah semua blok bagian rangkaian terhubung. Setelah alat terhubung dengan sumber listrik, berikutnya adalah membuka aplikasi pengontrolan pada smartphone android dan memunculkan layer pengontrolan. Sebelum membuka aplikasi pengontrolan kita harus terhubung dahulu dengan jaringan wireless yang terkoneksi dengan rangkaian Xboard V2.

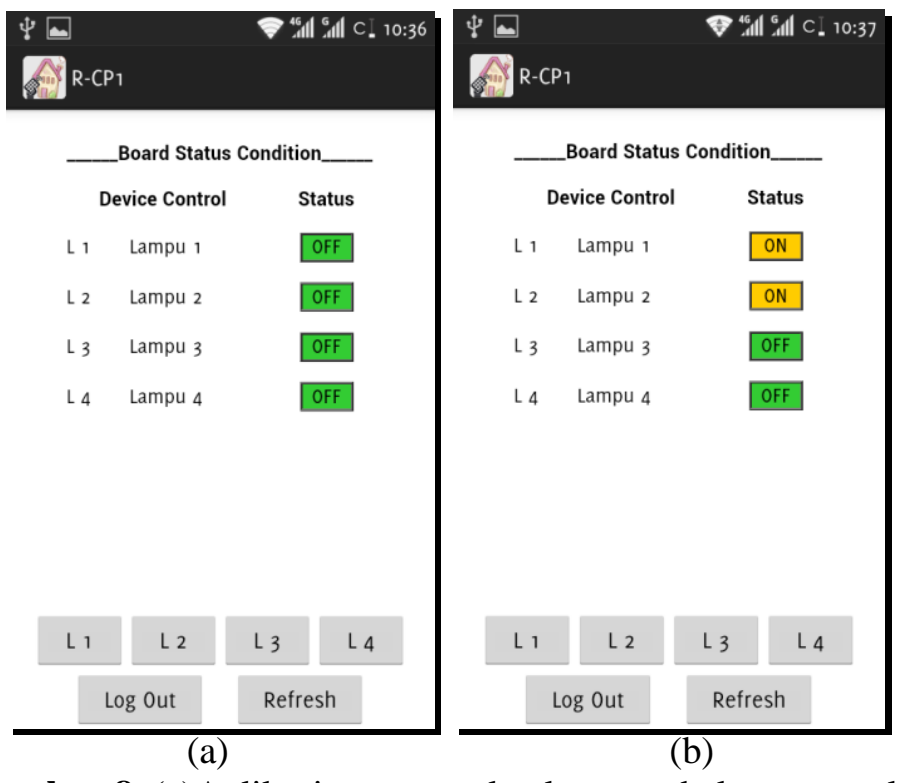

Gambar 8. (a)Aplikasi pengontrolan lampu sebelum menyala.

(b) Lampu setelah menyala.

Apabila status yang terdapat pada pengontrolan yang ditunjukkan pada gambar 8. berwarna hijau dengan teks status $O F F$ maka lampu dalam keadaan tidak menyala, sebaliknya saat status pengontrolan berubah menjadi warna kuning dan teks menjadi $O N$ maka lampu dalam keadaan menyala.

Tabel 1. Identitas Lampu.

\begin{tabular}{|c|c|c|c|}
\hline No & Nama Button & Nama Lampu & Identitas Lampu \\
\hline 1 & L1 & Lampu 1 & $\underline{\text { http://192.168.1.177/?LED1=1 }}$ \\
\hline 2 & L2 & Lampu 2 & $\underline{\text { http://192.168.1.177/?LED1=2 }}$ \\
\hline 3 & L3 & Lampu 3 & $\underline{\text { http://192.168.1.177/?LED1=3 }}$ \\
\hline 4 & L4 & Lampu 4 & $\underline{\text { http://192.168.1.177/?LED1=4 }}$ \\
\hline
\end{tabular}


Agar lampu yang kita kendalikan dapat terhubung dengan baik maka lampu harus memiliki identitas seperti pada tabel 1. Masing-masing lampu memiliki identitas yang berbeda-beda bertujuan agar pada saat pengontrolan, lampu yang kita kontrol tidak akan salah atau tertukar dengan lampu yang lain. Identitas lampu ini terembedded didalam program mikrokontroler ATMega328.

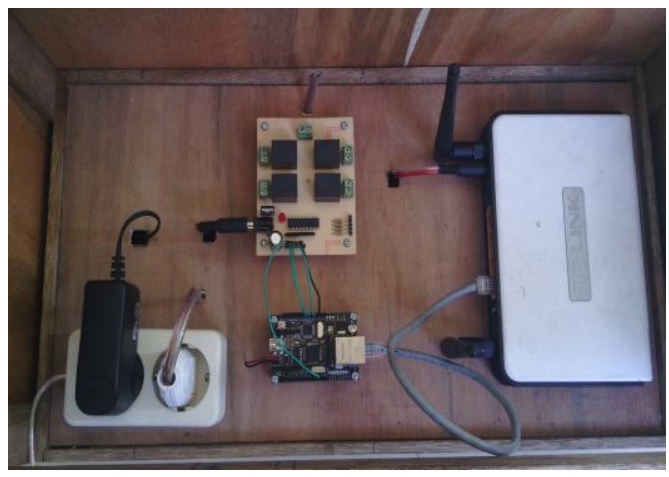

(a)

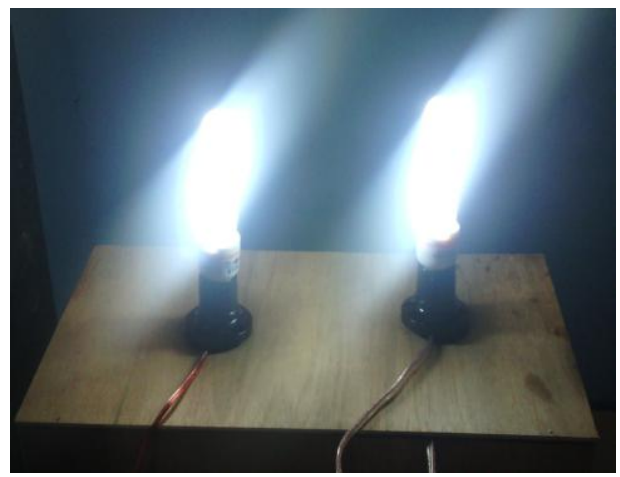

(b)

Gambar 8. (a) Tata letak rangkaian, (b) Kondisi lampu saat menyala

Tabel 2. Hasil uji coba aplikasi android menggunakan metode Black Box

\begin{tabular}{|c|c|c|c|c|}
\hline No & Nama Button & Nama Lampu & Kondisi awal & Kondisi Lampu \\
\hline 1 & L1 & Lampu 1 & 0 & Padam \\
\hline & & & 1 & Menyala \\
\hline 2 & L2 & Lampu 2 & 1 & Menyala \\
\hline & & & 0 & Padam \\
\hline 3 & L3 & Lampu 3 & 1 & Menyala \\
\hline & & & 0 & Padam \\
\hline 4 & L4 & Lampu 4 & 0 & Padam \\
\hline & & & 1 & Menyala \\
\hline
\end{tabular}

Keterangan: 1. Kondisi awal $0=$ Input Law

2. Kondisi awal $1=$ Input High

Dari data yang kita lihat pada tabel 2 menunjukkan bahwa aplikasi android mampu menghidupkan dan mematikan lampu sesuai dengan yang dituju. Jika pada button L1 ditekan maka lampu 1 akan bernilai 1 sehingga lampu 1 akan menyala dan untuk mematikan lampu kita menekan button yang sama yaitu button L1 maka lampu akan padam.

Tabel 3. Pengujian Rangkaian Relay Menggunakan Metode Black Box

\begin{tabular}{|c|l|c|c|}
\hline No & Nama & Nilai awal & Keterangan \\
\hline 1 & Relay 1 & 0 & NO \\
\hline & & 1 & NC \\
\hline 2 & Relay 2 & 1 & NC \\
\hline & & 0 & NO \\
\hline 3 & Relay 3 & 0 & NO \\
\hline & & 1 & NC \\
\hline 4 & Relay 4 & 0 & NO \\
\hline & & 1 & NC \\
\hline
\end{tabular}

Keterangan: 1. Kondisi awal 0 = Input Law

2. Kondisi awal 1 = Input High

3. $\mathrm{NC} \quad=$ Normali Close

4. NO= Normali Open

Pada saat relay tidak menerima input atau memiliki input bernilai 0 maka relay dalam kondisi NO (Normali Open) atau kondisi tidak terhubung. Apabila relay mendapatkan nilai 1 maka status NO 
berubah menjadi NC (Normali Close) atau kondisi terhubung dan relay dapat menyalakan lampu sesuai dengan input jalur yang masuk.

Tabel 4. Pengukuran Jarak Kontrol

\begin{tabular}{|c|c|l|}
\hline No & Jarak Kontrol & \multicolumn{1}{|c|}{ Keterangan } \\
\hline 1 & 3 Meter & Sinyal Sangat Baik \\
\hline 2 & 7 Meter & Sinyal Sangat Baik \\
\hline 3 & 10 Meter & Sinyal Baik \\
\hline 4 & 15 Meter & Sinyal lemah \\
\hline 5 & 18 Meter & Sinyal sangat lemah \\
\hline 6 & 20 Meter & Tidak ada sinyal \\
\hline
\end{tabular}

Pengujian jarak kontrol aplikasi android secara wireless didapat seperti pada tabel 4. Dapat kita lihat bersama bahwa jarak untuk pengontrolan yang baik secara wireless dengan jarak 15 meter, bila lebih dari 15 meter maka pengontrolan menjadi kurang baik karena sinyal sangat lemah bahkan aplikasi android tidak akan menangkap sinyal wireless. Jika aplikasi android tidak mampu menangkap sinyal wireless maka aplikasi android tidak mampu digunakan sebagai device pengontrol.

Setelah melakukan perancangan dan pengujian terhadap rangkaian, didapat bahwa rangkaian ini sudah berjalan dengan baik. Aplikasi pada Operating System android dapat memberikan input kepada mikrokontroler ATMega328 dan dapat memproses data dengan nilai output high atau law. Sehingga rangkaian driver ULN2803 dan rangkaian relay dapat menyalakan atau mematikan lampu.

\section{KESIMPULAN}

Dari evaluasi hasil kerja alat dapat diambil beberapa kesimpulan:

1. Smartphone dengan operating system android dapat digunakan sebagai alat pengontrolan secara nirkabel dan dalam pembuatan aplikasinya dapat disesuaikan dengan kebutuhan pengguna karena OS android merupakan salah satu OS open source. Sehingga pengontrolan dapat dilakukan pada ruang yang terpisah dan dapat memonitoring semua lampu yang terhubung pada aplikasi android ini.

2. Rangakaian Xboard V2 dapat digunakan sebagai jembatan komunikasi antara smartphone android dan mikrokontroler ATMega328 sehingga dapat mengontrol lampu dengan baik. Dengan menggunakan Xboard V2 membuat rangkaian pengontrolan menjadi sederhana karena didalam Xboard V2 sudah dilengkapi dengan 2 rangkaian utama yaitu Rangkaian Mikrokontroler ATmega328 dan rangkaian Wiznet W5100.

3. Output yang dapat dikendalikan oleh aplikasi android ini sebanyak 4 output, dari hasil uji coba yang dilakukan maka rangkaian ini sudah sesuai dengan tujuan awal yang direncanakan.

\section{SARAN}

Saran dari penelitian ini : 1) Disarankan dengan adanya peralatan control dengan mobile device based on android operating sistem ini dapat dipergunakan dan dimanfaatkan dengan baik agar kekurangan-kekurangan dalam menjalankan peralatan rumah tangga secara manual bisa dikurangi bahkan dihilangkan agar berjalan dengan efektif dan efisien. 2) Disarankan kepada setiap anggota rumah tangga untuk dapat menjalankan program mobile device based on android operating sistem ini agar ketika ingin meninggalkan rumah jauh dan lama semua peralatan listrik dapat terkontrol dengan baik, dan kita hanya perlu jaringan internet saja.

\section{UCAPAN TERIMAKASIH}

Penulis mengucapkan terimakasih kepada: Bpk. Ir. Untung Rahardja, M.T.I., selaku Ketua STMIK Raharja dan Bpk. Drs. PO.Abas Sunarya, M.Si.,selaku Direktur AMIK Raharja yang telah memberi dukungan financial terhadap penelitian ini. 


\section{DAFTAR PUSTAKA}

[1] Syahid. 2012. "Rancang Bangun Robot Beroda Berbasis Android Menggunakan Komunikasi USB". ISSN : 2252-4908 Vol. 1 No. 2 Agustus 2012 : 33-42.

[2] Abdus Salam, Mukhidin, Tasma Sucita. 2012. "Rancang Bangun Sistem Jaringan Multidrop Menggunakan Rs485 Pada Aplikasi Pengontrolan Alat Penerangan Kamar Hotel”. ELECTRANS, VOL.11, NO.2, SEPTEMBER 2012 , $1-11$.

[3] Adelia dan Jimmy Setiawan. 2011. "Implementasi Customer Relationship Management (CRM) pada Sistem Reservasi Hotel berbasisi Website dan Desktop". Jurnal Sistem Informasi, Vol. 6, No.2, September 2011.

[4] Budiman. 2012. "Pengujian Perangkat Lunak dengan Metode Black Box Pada Proses Pra Registrasi User Via Website", Makalah, halaman: 4.

[5] Ahmad Hanafie, Dimyati Thomsun, A. Wahyuni, Hikmah. 2009. "DESAIN SIMULASI SISTEM PENGONTROLAN LAMPU RUANGAN DENGAN PERSONAL KOMPUTER MELALUI PARALLEL PORT”. ILTEK, volume 4, Nomor 7, April 2009. 